\title{
Juvenile movement patterns in a territorial scorpaenid fish before and during settlement
}

\author{
Guy A. Hoelzer \\ Department of Ecology and Evolutionary Biology, University of Arizona, Tucson, Arizona 85721, USA
}

\begin{abstract}
The gopher rockfish Sebastes carnatus is a territorial resident of the kelp forests of central California. During summer, young-of-the-year recruit initially to the kelp canopy where they stay for about 1 to 2 mo prior to joining conspecific adults on the bottom. Movement patterns of these juveniles were studied in the kelp canopy. The juveniles tended to be site-attached in the kelp canopy even though there is no apparent advantage in this behavior in the canopy microhabitat. They also appear to explore new areas prior to shifting habitat. These and previous results suggest that there are fundamental behavioral similarities between pre-settlement juveniles and adults of the same species despite dramatic ecological changes due to growth and change of habitat.
\end{abstract}

Many organisms undergo dramatic changes in habitat and ecology as they pass from one life stage to another. This is particularly evident for marine organisms with planktonic larvae and demersal adults. The behavior of these organisms generally changes between stages in ways that seem to suit new conditions. However, the proximate causes of behavioral change between life history stages are not well understood. This is a particularly difficult topic to address because genetically-programmed changes in behavior, corresponding to the physical changes that can occur during metamorphosis, are difficult to differentiate from environmentally-induced behavioral modification. Optimally, the behavior of an individual would be modified to accomodate changes in habitat or the morphology of the individual. The purpose of this study was to reveal fundamental changes or consistencies in the behavior of juvenile gopher rockfish Sebastes carnatus as they settle from a pelagic existence to the substrate of the rocky reef where they become territorial.

The gopher rockfish is a viviparous species whose offspring are released into the plankton in early spring (Larson 1980a). The young return to kelp forests along the central California coast, USA, when they have reached ca $30 \mathrm{~mm}$ standard length (Hoelzer 1987). This event will be termed 'recruitment' in this paper. The giant kelp Macrocystis pyrifera forms a dense surface canopy during summer. The juvenile rockfish are cryptically colored in the canopy microhabitat where they remain for 1 to 2 mo (Carr 1983, pers. obs.). Eventually they move to the rocky substrate where they reside for the rest of their lives. This event will be called 'settlement'. They feed on suspended zooplankton until they settle to the bottom, at which time they begin to take demersal crustaceans such as shrimps and amphipods (Singer 1985, pers. obs.).

Two fundamental aspects of territorial behavior in this species are site-specificity and aggressive defence of resources (Hallacher 1977, Larson 1980a,b,c). These behaviors have not been observed in the juveniles prior to settlement. Hoelzer (1987) demonstrated that juveniles collected from the kelp canopy behave aggressively toward their images in a mirror. Indeed, the range of agonistic behaviors displayed by the juveniles was surprising. The only agonistic behavior employed by adults that was not performed by the juveniles was jaw-locking. Furthermore, neither the display of agonistic behaviors, nor the overall aggressive intensity of the individuals, changed during the 6 mo period when they would have become integrated into the demersal adult population in the field. Field observations of juvenile Sebastes carnatus movement patterns are reported here to elucidate whether site-specificity is a trait that appears during the time of settlement or, like aggressive behavior, the tendency to associate with a particular place occurs prior to experience with a rocky habitat.

Methods. Underwater observations of juvenile Sebastes carnatus were conducted at various times throughout the day and night from spring 1980 until spring 1982 during more than 200 SCUBA dives. These observations indicated that the dispersal pattern of the juveniles did not change throughout the day. The positions of individual juveniles in the kelp canopy were checked on 11 d between 7 July and 2 September 1981 
at Stillwater Cove, Carmel Bay, California (water depth $13 \mathrm{~m}$ ). Because the canopy regularly changes its shape and position relative to the bottom due to changing wave and current conditions, juveniles may lack stable reference points for the maintenance of home ranges. The most stable potential reference points appeared to be the sites where stipes from individual kelp plants reached the surface. The density of Macrocystis pyrifera in this area was about 0.3 plants $\mathrm{m}^{-2}$. I marked 3 kelp plants by tying surveyors tape just above the holdfasts. The marked plants were spaced ca $10 \mathrm{~m}$ apart, forming a triangular pattern. A hand net was used to capture 133 juveniles within $2 \mathrm{~m}$ of each plant in the top $3 \mathrm{~m}$ of the water column. Standard lengths of these individuals ranged from 26 to $51 \mathrm{~mm}$ (mean \pm SD: $38.2 \pm 4.8$ ).

Following capture, the fish were taken to the support boat where each individual was measured, tagged, and the species determined (see Anderson 1983 for a description of Sebastes carnatus in the juvenile stage). Tags were flexible plastic streamers (Floy Tag Co., Catalog \#FTSL-73), that were threaded through the dorsal musculature with a needle. Three different tag colors were used, one for each kelp plant. The tags were also numbered so that each tag was unique. The fish were then released at the original capture site.

Tag color, tag number, and estimated distance from the 'home plant' were recorded when tagged individuals were resighted during scan sampling surveys (Altmann 1974). Each survey lasted about $3 \mathrm{~h}$. If a juvenile was spotted within the stipes of its 'home plant' the distance from the original capture site was recorded as $0 \mathrm{~m}$. Each scan sampling survey consisted of swimming haphazard swaths through the kelp forest as well as inspecting individual kelp plants from the surface down to the substrate. Ca $50 \%$ of the survey time was concentrated within a few meters of the marked plants, and the other $50 \%$ was spent surveying the rest of the kelp forest at distances up to $50 \mathrm{~m}$ from the home plants. Additional juveniles were captured and tagged after each survey.

Results. The juveniles swam sluggishly when released following the field tagging procedure. One individual quickly fell prey to a yearling Sebastes paucispinis. They recovered quickly, however, and by the next day their movement appeared the same as those of untagged juveniles.

Of the Sebastes carnatus tagged, 37 individuals $(28 \%)$ were resighted at least once. Many of these were found more than once. A total of 63 sightings was made during this investigation (Fig. 1). On average, tagged juveniles occurred $1.1( \pm 2.1) \mathrm{m}$ from their home plants. The distance ranged from 0 to $10 \mathrm{~m}$, and $63.5 \%$ of the sightings were within the $2 \mathrm{~m}$ of the plants from which they were originally captured.

Tagged juveniles were often found in the vertical stipes of the kelp rather than in the horizontal surface canopy. One individual was spotted twice in $1 \mathrm{~d}$ : the first time at a depth of ca $9 \mathrm{~m}$, and $1 \mathrm{~h}$ later at $1.5 \mathrm{~m}$ depth. Six juveniles were sighted on the bottom. Five of these were associated with the holdfast of their home plant.

About half of the sightings occurred within 1 wk of original capture (Fig. 1). One individual was seen $36 \mathrm{~d}$ after release. Even after relatively long periods, the juveniles tended to be seen quite close to their home plants. There was no correlation between the time since tagging and distance from the home plant (Spearman's rank correlation: $r_{\mathrm{s}}=0.2385 ; p>0.05$ ).

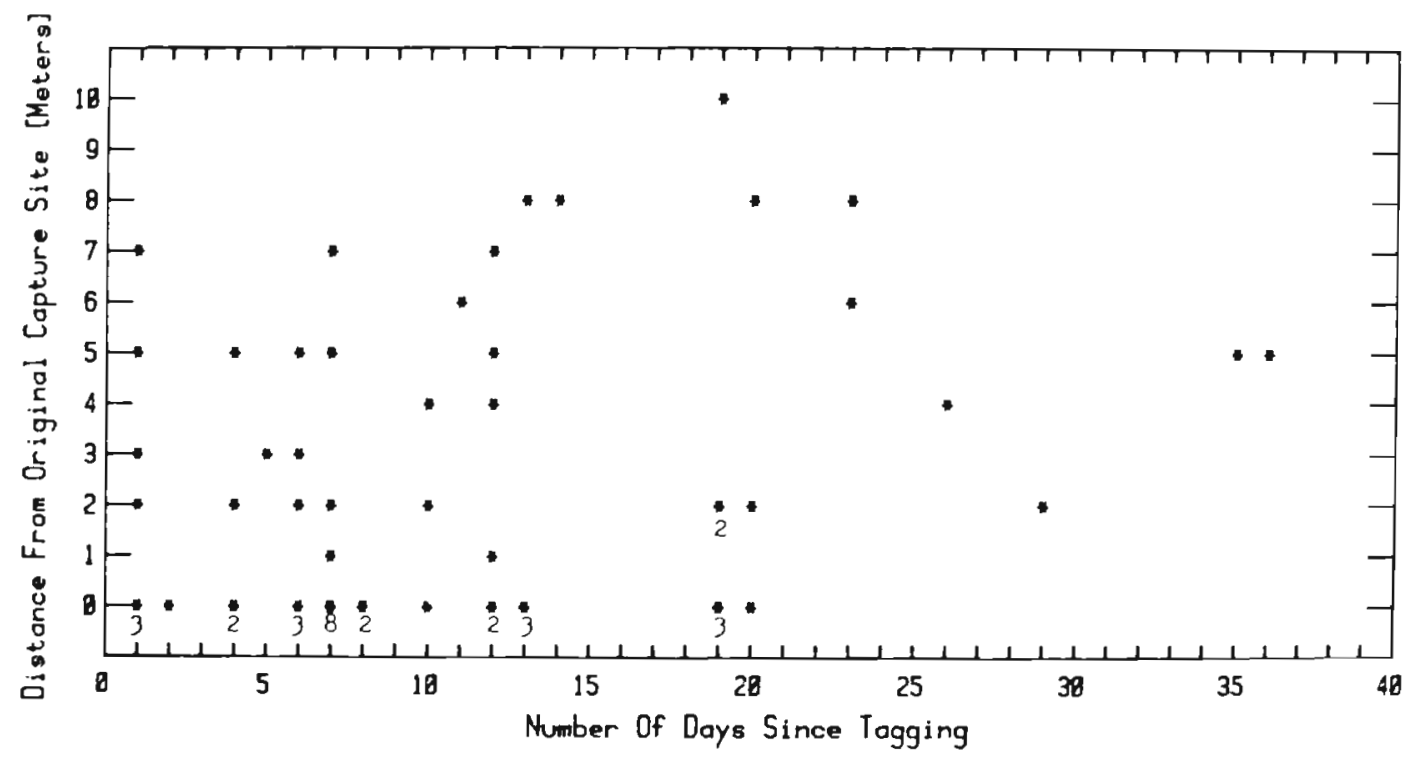

Fig. 1. Sebastes carnatus. Distance from the original capture site versus time since tagging for juveniles captured in the kelp canopy. If a point represents more than one resighting event, the number of resightings is given directly below 
Discussion. Many juvenile Sebastes carnatus tended to remain in one section of the kelp canopy while living in this habitat. Because search time was concentrated in and around the home plants, Fig. 1 does not represent the true dispersal pattern. Nevertheless, the frequency with which juveniles remained associated with specific kelp stipes was impressive because the shifting canopy and movement of the surface water would tend to disperse them. This does not necessarily imply that the 'home' plant has any special significance for an individual. It does demonstrate that individuals restrict their movements to a very limited portion of an apparently homogeneous habitat despite dispersive forces. Many of the juveniles that were not resighted after tagging were probably lost to mortality. Sea birds and yearling Sebastes paucispinis were commonly seen preying on the juveniles in the canopy (Ainley \& Sanger 1975). Furthermore, the density of juvenile $S$. carnatus decreased dramatically between the time of recruitment to the canopy and settlement on the bottom (pers. obs.). It has been suggested that the ability to learn the physical characteristics of a home range increases the chances of survival in juvenile salmonids on the substrate (Symons 1974). However, this would seem to be of little value in a laterally homogeneous environment in which the spatial relationships of different structures (e.g. kelp stipes) is constantly changing, such as in the canopy of a kelp forest. Site attachment of juvenile rockfish in the kelp canopy may represent a behavioral constraint that is expressed due to its adaptive value in the adult stage of life (Larson 1980b).

Juvenile Sebastes carnatus appear to explore before changing habitat. The results of the tagging experiment indicate that, after spending some time in the canopy, the juveniles begin to move down the stipes of the kelp plant that is closest to their position in the canopy. It is likely that the juveniles make many trips down the stipes before they relocate to the dense foliage around the holdfast as evidenced by the juvenile observed ascending the stipes. Juveniles were also observed moving horizontally away from the holdfasts on days with minimal wave surge. I interpret this behavior as individuals taking advantage of good conditions to explore the local substrate. These excursions probably help the rockfish to become familiar with the nearby substrate in the same way that trips down the stipes aid in the relocation to the holdfast. Larson (1980a) also noted that juveniles of these species moved over the substrate when they first appeared on the bottom. These observations indicate that it is important for the juveniles of these species to be familiar with their surroundings.

Casual observations of Sebastes carnatus juveniles in the field suggest great differences in life style between the surface canopy phase and the demersal phase. However, closer scrutiny reveals that fundamental behavioral traits, such as site specificity and possibly exploratory behavior, are expressed throughout both of these phases. Furthermore, Hoelzer (1987) demonstrated that aggressive behavior typical of the adults could be elicited from juveniles under suitable laboratory conditions. Thus, the behavioral metamorphosis that appears to accompany recruitment to the substrate in $S$. carnatus is likely to reflect the changing demands of a new environment rather than the development of a new behavioral program.

Acknowledgements. This work was completed in partial fulfillment of an MS degree at San Jose State University, San Jose, California by way of the Moss Landing Marine Laboratories. I thank T. Anderson, M. Carr, J. Heine, and M. Singer for field assistance. This work was partially supported by a grant from the Packard Foundation. G. Cailliet, R. Larson, and $\mathrm{B}$. Wurzig contributed to this work by serving as comittee members. A. Kodric-Brown, R. Larson, D. Thomson, and 4 anonymous reviewers provided particularly helpful comments on an earlier draft of this paper.

\section{LITERATURE CITED}

Altmann, J. (1974). Observational study of behavior: sampling methods. Behaviour 49: 227-265

Anderson, $T$ (1983). Identification and development of nearshore juvenile rockfishes (Genus: Sebastes) in Central California kelp forests. Masters thesis, California State Univ., Fresno

Ainley, D. G., Sanger, G. A. (1975). Trophic relations of seabirds in the northeastern Pacific Ocean and Bering Sea. U.S. Dept. Int., Fish Wildl. Serv., Wildl. Res. Rep. 11: 95-122

Carr, M. (1983). Spatial and temporal patterns of recruitment of young-of-the-year rockfishes (genus Sebastes) into a Central California kelp forest. Masters thesis, San Francisco State Univ., San Francisco

Hallacher, L. E. (1977). Patterns of space and food use by inshore rockfishes (Scorpaenidae: Sebastes) of Carmel Bay, California. Ph. D. dissertation, Univ. of California, Berkeley

Hoelzer, G. A. (1987). The effect of early experience on aggression in two territorial scorpaenid fishes. Environ. Biol. Fish. 19: $183-194$

Larson, R. J. (1980a). Competition, habitat selection, and the bathymetric segregation of two rockfish (Sebastes) species. Ecol. Monogr. 50: 221-239

Larson, R. J. (1980b). Territorial behavior of the black and yellow rockfish and the gopher rockfish (Scorpaenidae, Sebastes). Mar. Biol. 58: 111-122

Larson, R. J. (1980c). Influence of territoriality on adult density in two rockfishes of the genus Sebastes. Mar. Biol. 58: 123-132

Singer, M. (1985). Food habits of juvenile rockfishes (Sebastes) in a Central California kelp forest. Fish. Bull. U.S. 83: $531-541$

Symons, P. E. K. (1974). Territorial behavior of juvenile Atlantic salmon reduces predation by brook trout. Can. J. Zool. 52: $677-679$ 